\title{
BIBLIOTECA COMO RECURSO ESTRATÉGICO NO ESCRITÓRIO DE ADVOCACIA
}

\author{
Mariland Pires Pereira
}

\section{Resumo}

O avanço da tecnologia trouxe mudanças significativas em relação ao funcionamento das organizações. O ambiente competitivo agregou o uso da tecnologia e novos valores da informação como fonte de vantagem e de auxílio nos processos de tomadas de decisões nas organizações. Neste ambiente competitivo, a biblioteca também se faz necessária por ser vista como recurso estratégico, de modo a facilitar o controle e recuperação de informações essenciais à vida da organização de maneira eficiente e segura para seus usuários, além de elemento fundamental de vantagem competitiva para o escritório de advocacia.

\section{Palavras-chave}

Informação jurídica; Biblioteca jurídica; Gestão estratégica da informação

\section{LIBRARY AS A STRATEGICAL RESOURCE IN THE LAW OFFICE}

\begin{abstract}
The advance of technology brought on significative changes to the functioning of organizations. The competitive environment put together the use of technology and the new information values as source of advantage and help for decision making on organizations. In this competitive environment the library also makes itself necessary, being considered as a strategical resource to facilitate the control and retrieval of essential informations for the organization in an efficient and safe way. Besides, it is a fundamental component of competitive advantage of law offices.
\end{abstract}

\section{Key words}

Legal information; Law library; Strategic information management 


\section{INTRODUÇÃO}

O avanço da tecnologia trouxe para a sociedade mudanças significativas no que diz respeito ao funcionamento das organizações. Devido à inovações científicas e tecnológicas o eixo fundamental da economia passou a centrar-se mais na informação do que na força industrial para desenvolvimento da sociedade. A partir da década de 90, com o desenvolvimento da globalização, fatores como a abertura do mercado aos produtos estrangeiros, clientes e fornecedores mais exigentes influenciaram para que as organizações se tornassem mais competitivas e dinâmicas.

As organizações, face ao novo ambiente, agregaram o uso da tecnologia, não somente para garantir sua competitividade, mas sim para garantir sua sobrevivência. Não só se fez necessário o uso da tecnologia, como também, novos valores foram agregados à informação, que a partir da década de 90, passou a ser uma fonte de vantagem competitiva e de auxilio nos processos de tomadas de decisões nas organizações. A informação tornouse o diferencial não só para manter as organizações como para auxiliar nas organizações das tarefas do dia-a-dia. É necessário considerar que o sucesso da organização não depende somente das informações disponíveis, mas sim de saber coletar, organizar, analisar e implementar as mudanças mediante as informações que serão utilizadas para a melhoria contínua das atividades das organizações.

Com o crescimento e necessário uso das informações surgiu uma nova dificuldade, controlar esses estoques informacionais, a fim de que as informações fossem recuperadas e pudessem contribuir para o ambiente decisório. No caso do escritório de advocacia, a informação derivada de pesquisas doutrinárias, legislativas e jurisprudenciais, relatórios, dados dos clientes, necessitam muito mais do que um simples controle de informações, mas de pessoas capacitadas para que as informações possam ser arroladas e esejam disponíveis para a tomadas imediatas de decisões. Os bibliotecários têm o importante papel neste ambiente, pois entendem que informação e conhecimento são pontos importantes para o

(c) Revista Digital de Biblioteconomia e Ciência da Informação,Campinas v. 4, n..1, p. 19-37, jul./dez. 2006 - ISSN: 1678-65X. 
desenvolvimento de qualquer organização na obtenção de benefícios como qualidade, produtividade e competitividade não só para o objeto deste estudo, mas também para as organizações de maneira geral.

A gestão da estratégica da informação contribui para o desenvolvimento da informação no ambiente jurídico e defini o papel da biblioteca como elemento chave para a obtenção de benefícios como qualidade, produtividade e competitividade para o escritório de advocacia.

Este artigo é baseado no trabalho de pós-graduação em gestão estratégica apresentado à Universidade Cândido Mendes no intuito de abordar o papel da biblioteca como recurso estratégico auxiliando nos processos de tomada de decisão nos escritórios de advocacia e retratar a importância e necessidade do bibliotecário como agente facilitador do processo de recuperação da informação estratégica mediante a explosão informacional para o alcance da qualidade, produtividade e competitividade no escritório de advocacia.

\section{A INFORMAÇÃO}

Com as mudanças sociais ocorridas nos últimos 50 anos, dentre elas, o avanço da tecnologia, mudanças significativas ocorreram na economia, na sociedade e também no funcionamento das organizações.

\footnotetext{
Uma revolução tecnológica concentrada nas tecnologias da informação começou a remodelar a base material da sociedade em ritmo acelerado. Economias por todo o mundo passaram a manter interdependência global, apresentando uma nova forma de relação entre a economia, o Estado e a sociedade em um sistema de geometria variável. (CASTELLS, 2005, p. 39).
}

Para Castells (2005) no processo complexo de emergência de uma nova sociedade pósindustrial, o eixo fundamental da economia passou a centrar-se na informação e não mais na força industrial para o desenvolvimento da sociedade. Este autor ressalta, ainda, que a revolução atual, refere-se às tecnologias da informação, processamento e comunicação e a nova economia é caracterizada como global e informacional. 
No novo modo informacional de desenvolvimento, a fonte de produtividade acha-se na tecnologia de geração de conhecimentos, de processamento da informação e de comunicação de símbolos. [...] Contudo, o que é específico ao modo informacional de desenvolvimento é a ação de conhecimentos sobre os próprios conhecimentos como principal fonte de produtividade. O processamento da informação é focalizado na melhoria da tecnologia do processamento da informação como fonte de produtividade, em um círculo virtuoso de interação entre as fontes de conhecimentos tecnológicos e a aplicação da tecnologia para melhorar a geração de conhecimentos e o processamento da informação: é por isso que, voltando ä moda popular, chamo esse novo modo de desenvolvimento de informacional, constituído pelo surgimento de um novo paradigma tecnológico baseado na tecnologia da informação. (CASTELLS, 2005, p. 53-54)

Este autor ilustra um novo momento da sociedade, onde globalização, conhecimento e o avanço da tecnologia dão os novos contornos da sociedade. A atenção na nova economia se volta para a informação e suas aplicações como fator elementar para a produtividade. No decorrer da contextualização feita por Castells (2005), constata-se a necessidade de conceituar a informação e verificar sua importância.

\section{$1.2 \mathrm{O}$ conceito e a importância da informação}

Oportuno se torna consignar o conceito de informação, para que se possa compreender sua importância nas organizações. Barreto (1999) conceitua informação como sendo “conjuntos significantes com a competência e a intenção de gerar conhecimento no indivíduo, em seu grupo, ou na sociedade”. Partindo desse conceito, tem-se a informação como instrumento que modifica a consciência do homem e do seu grupo. Necessário se faz ressaltar a relação entre informação e conhecimento, que de acordo com o autor, só se revitaliza se a informação for percebida e aceita como tal, colocando o indivíduo sensível em um estágio melhor, consciente consigo mesmo e dentro do mundo de onde se realiza a sua mudança individual.

(c) Revista Digital de Biblioteconomia e Ciência da Informação,Campinas v. 4, n..1, p. 19-37, jul./dez. 2006 - ISSN: 1678-65X. 
Barreto (1999) ressalta ainda que o:

conhecimento é um processo, um fluxo de informação que se potencializa. Unidades de transferência de conhecimento formalizam um processo de transferência, assim o fluxo de conhecimento se completa ou se realiza, com a assimilação da informação pelo receptor em seu destino final.

Este autor afirma que a assimilação da informação é uma finalização de um processo de aceitação da informação, o qual transcende a disponibilidade, o acesso e uso da informação. A assimilação da informação faz realizar o fenômeno do conhecimento no indivíduo/receptor e em sua ambiência.

E este é o destino final da informação para Barreto (1999):

[...] criar conhecimento modificador e inovador no indivíduo e no seu contexto. Conhecimento, que o referencie tanto com o seu mundo de convivência, quanto com um melhor estágio de desenvolvimento. Porém, o indivíduo e sua realidade não são homogêneos. A realidade, na qual pretendemos que a informação atue gerando conhecimento, é fragmentada em suas condições políticas, econômicas e culturais. Os habitantes desta realidade são multifacetados em suas competências para absorver a informação.

Davenport (2002, p. 19), em seu livro, apresenta em forma de tabela os conceitos de dados, informação e conhecimento, onde dados são: "simples observações sobre o estado do mundo”, informações são: “dados dotados de relevância e propósito” e por último, conhecimento, “informação valiosa da mente humana”.

Segundo este autor, a informação não é facilmente arquivada em computadores e podem ter muitos significados em uma organização, além de estar baseada na maneira como as pessoas criam, distribuem e usam a informação. 


\begin{abstract}
Em vez de se concentrar na tecnologia, a ecologia da informação baseia-se na maneira como as pessoas criam, distribuem, compreendem e usam a informação. Administradores que possuem uma abordagem ecológica acreditam que:

. a informação não é facilmente arquivada em computadores - e não constituída apenas de dados;

. quanto mais complexo o modelo de informação, menor será sua utilidade;

. a informação pode ter muitos significados em uma organização;

- a tecnologia é apenas um dos componentes do ambiente de informação e freqüentemente não se apresenta como meio adequado para operar mudanças.(DAVENPORT, 2002, p. 14).
\end{abstract}

Ressalta ainda, que neste cenário de mudanças, um dos desafios para a organização é selecionar que dados e informações são úteis ao processo de formação e comunicação do conhecimento. À medida que as organizações fizerem a distinção entre dados, informação e conhecimento estarão agregando valores e oferecendo forças propulsoras para a consolidação da informação como matéria-prima nas organizações, além de estarem fornecendo base sustentável para o seu desenvolvimento e tomadas de decisões.

Aos olhos de McGee e Prusak (1994) a informação é um importante insumo estratégico, pois seu uso e exploração torna-se recurso fundamental para geração de conhecimento e fonte para desenvolvimento de novas oportunidades para as organizações. Os autores observam que informação é muito mais que dados processados, são “[...] dados coletados, organizados, ordenados, aos quais são atribuídos significados e contexto”. Releva destacar, que a informação não informa por si só, mas depende da manipulação do receptor, para que sejam utilizados.

A informação toma caráter estratégico a partir do momento que os dados são previamente atribuídos de significado. A informação para a empresa é um ativo que não se deteriora e é reutilizável sendo recurso básico para o desenvolvimento das atividades da organização, que uma vez que gerenciada dão suporte para que os gestores identifiquem as alternativas mais viáveis para as organizações.

Embora a informação seja um ativo que precisa ser administrado, da mesma forma que os outros tipos de ativos representados pelos seres humanos, capital, propriedades e bens materiais, ela representa uma classe particular dentre esses outros tipos de ativos. As diferenças decorrem do próprio potencial da 
informação, assim como do desafio de administrá-la ou gerenciá-la. A informação é infinitamente reutilizável, não se deteriora nem se deprecia, e seu valor é determinado exclusivamente pelo usuário; a fortuna de uns é a desgraça dos outros. (McGEE e PRUSAK, 1994, p. 23).

Os conceitos destes autores, norteiam a necessidade e importância da informação para o contexto da atual sociedade, baseada nas novas tecnologias.

É irrefutável, a relevância da informação como ferramenta de estratégia competitiva para as organizações, conforme McGee e Prusak (1994, p. 3): “[...] nas próximas décadas, a informação, mais do que a terra ou o capital, será força matriz na criação de riquezas e prosperidade. Nesse tipo de economia, o sucesso é determinado pelo que você sabe, e não pelo que você possui”.

\section{INFORMAÇÃO COMO RECURSO ESTRATÉGICO}

A informação, de acordo com as definições apresentadas no capítulo anterior, é considerada elemento primordial de vantagem competitiva para as organizações. É elemento primordial de apoio às estratégias e tomada de decisão, pois gera mudanças e integra a organização. Diga-se de passagem, que nos últimos anos vários investimentos foram feitos para que fornecesse a base sólida para as tomadas de decisões.

\subsection{Informação e estratégia}

O conceito de estratégia remonta ao meio militar onde as estratégias estavam relacionadas ao planejamento e direção das operações militares para que pudessem obter margem vantajosa em relação ao inimigo. O uso da estratégia ganhou força no meio empresarial usada para obter vantagem competitiva na preferência dos consumidores.

Vários estudiosos alçaram mão de escolas que refletiam as visões da estratégia nas organizações, mas segundo Mintzberg (2003, p. 24): 


\begin{abstract}
A estratégia pode ser vista como uma força mediadora entre a organização e seu ambiente. Por essa razão, a formulação da estratégia envolve a interpretação do ambiente e o desenvolvimento de padrões organizacionais (estratégias) para lidar com essa estratégia principal.
\end{abstract}

Nesta obra, o autor, assinala a importância de que as estratégias adotadas sejam sempre reavaliadas evitando, assim, que as organizações se percam no meio do planejamento.

Há ainda a necessidade de reavaliar o ambiente externo e interno para que as organizações não sejam pegas de surpresa por alteração dos aspectos e componentes dos ditos ambientes.

Neste ínterim, a informação é elemento primordial para as etapas de qualquer estratégia. Para a tomadas de decisões ou elaboração de estratégias, as informações devem estar atualizadas, com relação à análise do ambiente externo ou interno, os pontos fracos e fortes, as ameaças e oportunidades para que sejam suporte atualizado a fim de garantir o sucesso das organização.

\title{
3.2 A informação como fator de competitividade
}

Com a abertura do mercado, tanto os clientes quanto os fornecedores ficaram cada vez mais exigentes e as organizações foram submetidas às pressões por se sentirem ameaçadas pela concorrência nacional e internacional.

Portanto houve a necessidade de se conhecer o ambiente externo e interno tornando-se essencial para a sobrevivência das organizações. Por mais que o ambiente externo, não possa ser modificado, resta apenas monitorá-lo a fim de que a organização não seja surpreendida por medidas que venham a afetar seu desenvolvimento. Já o ambiente interno, torna-se necessário dominá-lo para que reflita o sucesso da organização.

Dentre os recursos necessários para a definição da estratégia está a informação, como elemento diferencial na organização, como retrata McGee e Prusak (1994, p. 58): 
A criação de produtos e serviços que os clientes julgavam únicos torna-se cada vez mais importante no ambiente de negócios da atualidade, que vem enfatizando a qualidade. A informação desempenha um papel especialmente importante no desenvolvimento de esforços para criar e manter a diferenciação. No momento da interação entre a empresa e o cliente, a informação torna-se um instrumento essencial para a individualização do serviço ao cliente num mundo anônimo.

Como visto, as organizações, para serem competitivas, deverão estar atentas ao ambiente externo e interno, para que as estratégias formuladas possam trazer o sucesso almejado e ser referência nos produtos e serviços oferecidos.

\subsection{A organização na geração de conhecimento}

Presente em todas as atividades da organização, a informação é insumo essencial para se obter a vantagem competitiva, conforme McGee e Prusak (1994, p. 71), ressaltam que “a obtenção de vantagem competitiva é a razão fundamental para o uso estratégico da informação".

A organização também é responsável pela produção de informações, uma vez que estimula o conhecimento interno e utiliza as informações produzidas devido a análise do ambiente externo.

De acordo com Davenport e Prusak (1998), a única vantagem sustentável que uma empresa tem é aquilo que ela coletivamente sabe, a eficiência com que ela usa e o que sabe e a prontidão com que ela adquire e usa os novos conhecimentos. As organizações usam o próprio conhecimento como fonte, ou seja, as organizações reconhecem que o conhecimento contido na própria organização as mantém competitivas.

Davenport e Prusak (1998) definem o conhecimento organizacional como:

(c) Revista Digital de Biblioteconomia e Ciência da Informação,Campinas v. 4, n..1, p. 19-37, jul./dez. 2006 - ISSN: 1678-65X. 
[...] uma mistura fluída de experiência condensada, valores, informação contextual e insight experimentado, a qual proporciona uma estrutura para a avaliação e incorporação de novas experiências e informações. Ele tem origem e é aplicado na mente dos conhecedores. Nas organizações, ele costuma estar embutido não só em documentos ou repositórios, mas também em rotinas, processos, práticas e normas organizacionais. (DAVENPORT e PRUSAK, 1998, p. 6).

Mediante a interatividade dos ambientes, as organizações produzem, absorvem e transformam as informações em conhecimento, pois sem esse não conseguiriam sequer funcionar. Para Davenport e Prusak (1998, p. 63-4), cinco são as formas de se produzir conhecimento nas organizações: aquisição, recursos dirigidos, fusão, adaptação e rede de conhecimento.

Na aquisição, pela compra, “isto é, adquirir uma organização ou contratar indivíduos que o possuam”, o conhecimento não precisa ser recém-criado ou original, o que importa é que seja novidade para a empresa. Além de comprado, também pode ser alugado ou financiado, geralmente ocorre na pesquisa, onde o apoio financeiro é dado em troca do uso comercial. (DAVENPORT e PRUSAK, 1998, p. 65).

Os recursos dirigidos são os de pesquisa dirigida, onde os departamentos de pesquisa e desenvolvimento são exemplos de como surge um novo conhecimento na organização.

Na fusão, a diversidade cognitiva se une, com valores e idéias diferentes e chegam a uma solução. “As sessões empregam regras específicas de comportamento, papéis do facilitador definidos e variada gama de input”. (DAVENPORT e PRUSAK, 1998, p. 74).

A adaptação, onde as mudanças são os motores de propulsão, se adaptam e assim evoluem. "Novos produtos de concorrentes, novas tecnologias e mudanças sociais e econômicas incentivam a geração do conhecimento porque as empresas que não se adaptarem às mudanças nas condições vigentes certamente fracassarão". (DAVENPORT e PRUSAK, 1998, p. 76). 
As redes de conhecimento são encontros informais e auto-organizados, que acontecem nas empresas que buscam soluções para problemas semelhantes. "Comunidades de possuidores do conhecimento acabam se aglutinando motivados por interesses comuns, e em geral conversam pessoalmente, por telefone e pelo correio eletrônico e groupware para compartilhar o conhecimento e resolver problemas em conjunto". (DAVENPORT e PRUSAK, 1998, p. 79).

Conclui os autores, que a geração do conhecimento nas empresas acontece de acordo com os esforços de cada um no intuito de trocarem conhecimento. Eles partem da premissa de que "o maior ativo de uma empresa é o conhecimento, a empresa que deixar de gerar conhecimento novo muito provavelmente deixará de existir”. (DAVENPORT e PRUSAK, 1998, p. 81).

\section{BIBLIOTECA COMO RECURSO ESTRATÉGICO NO ESCRITÓRIO DE ADVOCACIA}

A área jurídica, ao longo da última década, se fez sentir no mercado brasileiro devido às mudanças ocorridas advindas da globalização que aumentou significativamente as áreas de atuação dos escritórios devido aos fatores assinalados por Selem:

\footnotetext{
Os escritórios de advocacia perceberam os efeitos do fenômeno da globalização através do aumento da demanda por serviços jurídicos mais especializados, das facilidades e rapidez na comunicação, e das alterações no perfil da atividade econômica dos clientes, o que, numa análise superficial, pode significar grandes oportunidades. (SELEM, 2003, p. 35).
}

Mas as oportunidades podem virar obstáculos se as ações administrativas não forem planejadas com cautela. É importante ressaltar que as análises dos ambientes, tanto externo quanto interno, são necessárias para que se tenha uma visão global da organização a fim de definir objetivos claros para o sucesso da empresa.

Ocorre que, de oportunidades, tais efeitos podem se transformar em ameaças, caso os recursos humanos e financeiros não sejam otimizados; caso não se atente

(c) Revista Digital de Biblioteconomia e Ciência da Informação,Campinas v. 4, n..1, p. 19-37, jul./dez. 2006 - ISSN: 1678-65X. 


\begin{abstract}
ao controle rigoroso na qualidade dos serviços; caso não se atinja uma alta performance técnica; enfim, caso as ações administrativas não sejam devidamente planejadas. (SELEM, 2003, p. 36).
\end{abstract}

Neste ínterim, se faz necessário para o escritório de advocacia, que aos elementos humanos sejam agregados valor, para que se tornem diferencial neste mercado que vem crescendo em competitividade. De acordo com Davenport (1998, p. 9) "quando as empresas contratam especialistas, elas estão comprando insights baseados na experiência”.

Na busca pela excelência os escritórios de advocacia estão modificando o uso de seus recursos estratégicos. Alguma atenção tem sido dada a Gestão do Conhecimento, mas ainda não se tem uma postura única com relação a esse conceito, por não ser considerada uma atividade essencial e, facilmente eliminada para manter a rentabilidade da empresa. Mas, vários são os escritórios que estão atribuindo ao uso da Gestão do Conhecimento sucesso em suas atividades mais essenciais.

\title{
4.1 Gestão do conhecimento na área jurídica
}

No caso jurídico, a gestão do conhecimento tem se transformado no diferencial para vários escritórios. Potencializar o capital intelectual representa, neste momento, a maior força da empresa.

Os advogados têm se preocupado com atividades da produção de conhecimento recorrendo com freqüência ao auxílio bibliotecário na tarefa de pesquisa seja doutrinária, jurisprudencial ou legislativa a fim de manter seu foco no atendimento diferenciado de seu cliente e na construção de um relacionamento produtivo com eles.

Neste cenário, se faz importante saber que o escritório, baseia-se em conhecimento e este deve ser encarado como recurso estratégico potencializando o capital intelectual.

Para Selem,

(c) Revista Digital de Biblioteconomia e Ciência da Informação,Campinas v. 4, n..1, p. 19-37, jul./dez. 2006 - ISSN: 1678-65X. 
[...] quando o êxito é baseado no aprendizado, as pessoas são fundamentais para a empresa, caso se trate de uma empresa de serviços jurídicos. Afinal, o conhecimento está armazenado na mente das pessoas, dos advogados. É preciso um novo modo de pensar sobre como medir o sucesso nos escritórios de advocacia, uma vez que esse depende da habilidade em gerir pessoas e fazê-las desenvolver uma consistente base de conhecimentos que faça do capital intelectual acumulado a maior riqueza construída num escritório jurídico. (SELEM, 2005, p. 1).

Organizar a informação jurídica tornou-se ponto primordial para escritórios de advocacia, pois recuperar com rapidez e eficiência as informações trouxe benefícios como qualidade, aumento da produtividade e competitividade, como expõe Rezende (1998):

Não basta, portanto, ter disponíveis as informações, em alguns casos isto pode até dificultar ainda mais os resultados. É preciso que as informações disponibilizadas estejam organizadas e acessíveis a tempo de vencer os prazos e a concorrência. (p. 72).

\subsection{A informação jurídica na biblioteca}

Existem diversos conceitos para informação jurídica, mas Barreto (2002) especifica a informação jurídica em três tipos de documentos: a produção jurídica do escritório, a produção intelectual e Doutrina, legislação e jurisprudência.

Para Barreto (2002, p. 4) a produção jurídica é a “documentação gerada internamente para atender os casos, operações e projetos dos clientes”. Esta produção representa o conhecimento interno da empresa e corrobora para o crescimento como um todo da biblioteca, no entanto ATIENZA (1979 apud REZENDE, 2003, p. 3) complementa que documentação jurídica é “a reunião, análise e indexação da doutrina, da legislação, da jurisprudência e de todos os documentos oficiais relativos a atos normativos ou administrativos”.

Por produção intelectual, Barreto (2002, p. 4) entende como sendo “[...] documentação de caráter opinativa escrita pelos sócios e editada em forma de pareceres, teses, artigos 
publicados em revistas e jornais, 'papers' e apresentações em eventos de diversas naturezas”.

Esta produção vem aos poucos criando novas oportunidades e diferenciando os escritórios no mercado. Escritórios atualizados captam clientes, pois investir no desenvolvimento intelectual traduz em criar ambientes voltados para o atendimento diferenciado ao cliente.

E por último Doutrina, legislação e jurisprudência:

[...] e outros tipos de documentos, gerados externamente, que sejam tanto de caráter referencial como opinativo, presentes em livros, revistas, teses e pareceres especializados. As pesquisas são feitas em diferentes fontes de informação, disponibilizadas em formatos diferentes, demandando tempo e esforço para reunir o conhecimento desejado, em tempo hábil. (p. 4)

O processo de tomada de decisões acontece nas ações do cotidiano. A importância de se ter informações organizadas parte do princípio de que estruturadas, atualizadas e à disposição podem facilitar a análise e reduzir as incertezas e o riscos provocados pela decisão, como ressalta Rezende (2000, p. 2):

\footnotetext{
Neste novo contexto, a tecnologia da informação pode ser considerada uma das principais ferramentas a serem utilizadas para obtenção de ganhos de qualidade e produtividade, principalmente se considerarmos sua rapidez e confiabilidade. Hoje, as empresas têm investido muito mais em pesquisas, com vistas a criar sistemas de informação que atendam às suas necessidades específicas, permitindo o acesso ao máximo de informações relevantes ao decisor.
}

O uso de informações e conhecimento atuam na compreensão do problema, nas alternativas de solução e na avaliação dos resultados.

A biblioteca jurídica torna-se um diferencial competitivo para os escritórios, pois mantém seu foco que é a busca e a disseminação da informação jurídica, além da organização do conhecimento provenientes das diversas fontes. Auxilia, com o auxílio do bibliotecário, as tomadas de decisões tanto nos processos jurídicos, como também, no atendimento aos clientes, além de evitar controvérsias e duplicidade de informações prestadas gerando 
segurança e confiabilidade das informações por parte dos clientes.

\title{
4.3 A importância do bibliotecário e os benefícios para os escritórios de advocacia
}

Davenport (1998) assinala as várias competências dos profissionais que atuam na área do conhecimento. Ressalta que, as habilidades de organização e classificação, próprias do bibliotecário, podem constituir um diferencial competitivo nas organizações.

\begin{abstract}
Ainda que o papel do bibliotecário possa incluir a difusão de dados, ele está mais habilitado a lidar com conteúdos. Bibliotecários estão mais familiarizados com as informações com que lidam que a maior parte dos profissionais da informação. Administrando não só com informações de fontes internas, mas também as obtidas externamente, bibliotecários empresariais começaram a expandir o escopo de suas atividades e a trabalhar mais diretamente com os usuários. Dessa forma, souberam usar seus serviços para conferir vantagem competitiva à empresa. (DAVENPORT, 2002, p. 142).
\end{abstract}

Afirmam Davenport e Prusak (1998) que os "bibliotecários freqüentemente agem como corretores do conhecimento disfarçados, apropriados, por seu temperamento e seu papel de guia de informações, para a tarefa de criar contatos pessoa-pessoa e pessoa-texto". (DAVENPORT e PRUSAK; 1998, p. 34).

Segundo Passos (2001, p. 1) o "bibliotecário jurídico é o profissional que facilita o acesso à informação jurídica de forma ágil e eficiente”. Dentro dessa ótica, percebe-se que o bibliotecário, devido a sua formação específica é o profissional especialista que possui habilidades para lidar com a informação. Loureiro (2005) complementa que “[...] sua formação acadêmica o credencia para organizar massas documentais, habilitando-o com as técnicas de tratamento da informação geral e/ou específica”.

Segundo a American Association of Law Libraries (apud. PASSOS, 2001, p. 1), os bibliotecários jurídicos são:

. atentos às fontes de informação indiferente ao seu suporte; . astutos juizes das vantagens e desvantagens de várias fontes de informação;

(c) Revista Digital de Biblioteconomia e Ciência da Informação,Campinas v. 4, n..1, p. 19-37, jul./dez. 2006 - ISSN: 1678-65X. 
. capazes de organizar a informação para que possa ser localizada e utilizada independentemente do seu suporte;

. especialistas no uso de fontes jurídicas ou não.

Dessa forma, nos escritórios de advocacia, a função do bibliotecário, é a de auxiliar o trabalho intelectual dos advogados e funcionários, com as tarefas de pesquisa, além do tratamento técnico dos materiais bibliográficos inerentes ao suporte da biblioteca.

Dentre as principais competências do bibliotecário estão, a economia de tempo do advogado na pesquisa executada, a busca pela amplitude do assunto nos mais variados suportes aumentando a qualidade da pesquisa, avaliar a autenticidade do material coletado, manter a comunidade jurídica atualizada com relação aos novos materiais e suportes de informação, estar atualizado com as tendências da área jurídica, dentre outras, que assinalam a importância de agregar valor ao trabalho bibliotecário como requisito imprescindível de vantagem competitiva dentro do escritório de advocacia.

\section{CONCLUSÃO}

Este trabalho teve o intuito de contribuir com a área de gestão estratégica da informação no que diz respeito à necessidade e importância da biblioteca como recurso estratégico para o escritório de advocacia.

Os avanços da tecnologia permitiram que organizações e indivíduos percebessem a importância da informação em suas atividades. A informação, no contexto atual da sociedade, passou a nortear os fatores qualidade, produtividade e competitividade, em busca de vantagem competitiva para garantir o sucesso das empresas.

Devido às novas perspectivas das organizações, os escritórios, estão adaptando suas necessidades devido a importância de se ter informação rápida e precisa para as tomadas de decisão, seja aplicado aos clientes ou mesmo às atividades cotidianas.

(c) Revista Digital de Biblioteconomia e Ciência da Informação,Campinas v. 4, n..1, p. 19-37, jul./dez. 2006 - ISSN: 1678-65X. 
No escritório de advocacia, a biblioteca e o bibliotecário, tornam-se diferenciais no que se refere à vantagem competitiva. Ter as informações organizadas e fáceis de serem recuperadas com rapidez e eficiência abriu um novo leque aos escritórios, que contam com o apoio de profissionais específicos para o tratamento e recuperação da informação necessária ao trabalho jurídico.

\section{REFERÊNCIAS}

BARRETO, A. A. A oferta e a demanda da informação: condições técnicas, econômicas e políticas. Disponível em: <http://www.e-iasi.org.br/cinfor/sensivel.htm>. Acesso em: 14 set. 2005.

CASTELLS, M. A sociedade em rede. São Paulo: Paz e Terra, 2005. v. 1

DAVENPORT, T. D. Ecologia da informação: porque só a tecnologia não basta para o sucesso na era da informação; tradução Bernadete Siqueira Abrão. São Paulo: Futura, 2002.

DAVENPORT, T. D.; MARCHAND, D. A.; DICKSON, T. Dominando a gestão da informação. Porto Alegre: Bookman, 2004.

DAVENPORT, T. D.; PRUSAK, L. Conhecimento empresarial: como as organizações gerenciam o seu capital intelectual. Rio de Janeiro: Campus, 1998.

LOUREIRO, R. C. C. A especialidade do bibliotecário jurídico: bases para uma interação com o usuário operador do direito. Disponível em: <http://www.infolegis.com.br>. Acesso em: 17 jun. 2005.

McGEE, J.; PRUSAK, L. Gerenciamento estratégico da informação: aumente a competitividade e a eficiência de sua empresa utilizando a informação como uma ferramenta estratégica. Rio de Janeiro: Campus, 1994.

(c) Revista Digital de Biblioteconomia e Ciência da Informação,Campinas v. 4, n..1, p. 19-37, jul./dez. 2006 - ISSN: 1678-65X. 
MINTZBERG, H. Criando organizações eficazes: estrutura em cinco configurações. 2.ed. São Paulo: Atlas, 2003.

PASSOS, E. Bibliotecário jurídico: seu perfil, seu papel. 2001. Disponível em: <http://www.infolegis.com.br>. Acesso em: 17 ago. 2005.

REZENDE, Ana Paula. Centro de informação jurídica eletrônico e virtual. Ci. Inf. [online]. Brasilia, v. 29, n. 1, jan./apr. 2000, p. 51-60. Disponível em: <http://www.scielo.br/> Acesso em: 23 jan. 2006.

REZENDE, M. I. S. D. Gerenciamento da informação e do conhecimento jurídico. Disponível em: <http://www.prgo.mpf.gov.br/prgonova/doutrina/Martha-13.html>. Acesso em: 13 out. 2003.

REZENDE, M. I. S. D. Gerenciamento da informação e do conhecimento no escritório de advocacia. In.: CIBERÉTICA. SIMPÓSIO INTERNACIONAL DE PROPRIEDADE INTELECTUAL, INFORMAÇÃO E ÉTICA, 1, 1998, Florianópolis. Anais... Florianópolis, SC, 19 a 21 nov. 1998.

SARMENTO, A. G. S.; ROSA, A. G. M. F.. Informação jurídica: valor agregado: O quê? Por quem? E para quem? In: ENCONTRO NACIONAL DE DOCUMENTAÇÃO E INFORMAÇÃO JURÍDICA, 7, 2000. Porto Alegre. Anais... Porto Alegre, 2000.

SELEM, L. C. A. Estratégia na advocacia: planejamento para escritórios de advocacia. Curitiba: Juruá, 2003.

SELEM, L. C. A. A reinvenção da advocacia. Disponível em: <http://www.uj.com.br>. 
ARTIGO

\section{Mariland Pires Pereira}

Graduada em Biblioteconomia e Documentação pela Universidade Federal Fluminense Pós-graduação em Gestão Estratégica pela Universidade Cândido Mendes.

pmariland@yahoo.com.br 